\title{
Division IV: Stars
}

\section{PRESIDENT: Dainis Dravins \\ ORGANIZING COMMITTEE: Beatriz Barbuy, Christopher Corbally, Wojciech Dziembowski, William Hartkopf, Christopher Sneden, and Monique Spite}

The IAU Division IV ('Stars') organizes astronomers studying the characteristics, interior and atmospheric structure, and evolution of stars of all masses, ages, and chemical compositions.

During the triennial starting at the Sydney General Assembly in August 2003, the following officials served in Division IV: President - Dainis Dravins (Lund, Sweden); Organizing Committee - Beatriz Barbuy (São Paolo, Brazil; former Div.IV president); Christopher Corbally (Vatican \& Tucson, USA; Comm. 45 President); Wojciech Dziembowski (Warsaw, Poland; Comm. 35 President); William Hartkopf (Washington DC, USA; Comm. 26 President); Christopher Sneden (Austin, USA; Comm. 29 President), and Monique Spite (Paris-Meudon, France; Comm. 36 President).

\section{IAU DIVISION IV}

Division IV has its origins in the then new division structure that was introduced on a trial basis at the General Assembly in the Hague 1994, becoming formally accepted at the Kyoto General Assembly in 1997. Previous presidents of Division IV have been: David L. Lambert (Austin; 1994-1997), Lawrence Cram (Sydney; 1997-2000), and Beatriz Barbuy (São Paolo; 2000-2003).

The following five Commissions are part of Division IV:

Commission 26: Double and Multiple Stars (about 110 members)

Commission 29: Stellar Spectra (about 340 members)

Commission 35: Stellar Constitution (about 330 members)

Commission 36: Theory of Stellar Atmospheres (about 330 members)

Commission 45: Stellar Classification (about 130 members)

There are four Division Working Groups, of which two jointly with Division V - Working Group on Abundances in Red Giants; Working Group on Massive Stars; Joint Division IV/V Working Group on Active OB Stars, and Joint Division IV/V Working Group on Chemically Peculiar and Related Stars.

Two Working Groups exist within Commissions: Comm. 26 Working Group on Binary and Multiple System Nomenclature, and Comm. 45 Working Group on Standard Stars.

\section{SCIENTIFIC MEETINGS}

One of the main tasks of the Division (besides all the work within its Commissions!) has been to evaluate proposals for IAU meetings, and to advise the IAU Executive in their selection. Based upon the experience from this process (which in the past has not always been very simple nor straightforward), ideas for simplification were developed. Part of the problems was related to the traditional subdivision of astronomical topics within the IAU Commission and Division structure. Possibly, the Division 'Stars' has stronger overlaps to other Divisions than most other fields, and the closeness in scientific 
goals and in the methods for reaching them at times makes the distinction between a few of these Divisions appear somewhat artificial.

Efforts were made to simplify and clarify the procedures for IAU meetings, and following discussions within various IAU bodies, a substantial streamlining was approved by the IAU Executive in early 2005. For the nearest future, Division IV is enthusiastically looking forward to the Prague General Assembly, where a very broad program on stellar physics is being planned.

\section{CUTTING ACROSS DIVISION BOUNDARIES}

The scientific interests of Div.IV have strong connections with those of some other Divisions, especially Div.V ('Variable Stars') with which it has two joint Working Groups. It also has a strong connection to Div.II ('Sun and Heliosphere') as well as Div.VII ('Galactic System').

Already in the first Div.IV triennial report (IAU Trans. XXIII A, 1997), the then Division president David L. Lambert noted how often a discovery spreads across Commission and Division boundaries.

For example, consider the study of stellar oscillations in 'ordinary' solar-type stars. Prime scientific aims concern the study of stellar atmospheres and interiors, thus clearly belonging to our Div.IV. However, since the study is of variability, might it not instead 'belong' to Div.V, 'Variable Stars'? However, on the observational precision levels now reached, virtually all stars are variable but surely not all stars are to be referred to that Division? Actually, much of this new stellar physics is basically an application of solar techniques, so the methods may more belong to Div.II, 'Sun and Heliosphere'. Or, come to think of it, since oscillation studies emerge from the development of methods for very precise measurements of apparent stellar radial velocity, would the topic better fit within Comm. 30 'Radial Velocities' and its Division IX, 'Optical and Infrared Techniques'?

The Div.IV Commission 26, 'Binary and Multiple Stars' has a Working Group on Binary and Multiple System Nomenclature, justified i.a. by the numerous different methods through which stellar companions are now being detected. Planetary-mass companions are being found close to their parent stars, while adaptive-optics and interferometric techniques reveal close companions, in the past not resolvable optically: where is the borderline (if any) to Comm. 42, 'Close Binary Stars' within Division V, 'Variable Stars'?

Such examples show that the partition between (especially) Divisions IV and V exists mainly for historical reasons.

\section{REPORTS FROM COMMISSIONS AND WORKING GROUPS}

Further information on stellar physics, including web addresses for the various Commissions and Working Groups are to be found in their respective reports. However, while electronic communication is rapid, so is the rate of change of electronic addresses. The addresses listed in the reports below were active at the time of writing; however many officials will change following the General Assembly in Prague, as will the web addresses for the various bodies. The reader is therefore advised to consult the IAU website http://www.iau.org for the most current links to various Divisions, Commissions, and Working Groups. 